\title{
Beckwith-Wiedemann and IMAGe syndromes: two very different diseases caused by mutations on the same gene
}

This article was published in the following Dove Press journal:

The Application of Clinical Genetics

16 September 2014

Number of times this article has been viewed

\author{
Donatella Milani' \\ Lidia Pezzani' \\ Silvia Tabano ${ }^{2}$ \\ Monica Miozzo 2,3 \\ 'Pediatric Highly Intensive Care Unit, \\ Department of Pathophysiology and \\ Transplantation, Università degli Studi \\ di Milano, Fondazione IRCCS Ca' \\ Granda Ospedale Maggiore Policlinico, \\ ${ }^{2}$ Department of Pathophysiology and \\ Transplantation, Università degli Studi \\ di Milano, ${ }^{3}$ Division of Pathology, \\ Fondazione IRCCS Ca' Granda \\ Ospedale Maggiore Policlinico, \\ Milan, Italy
}

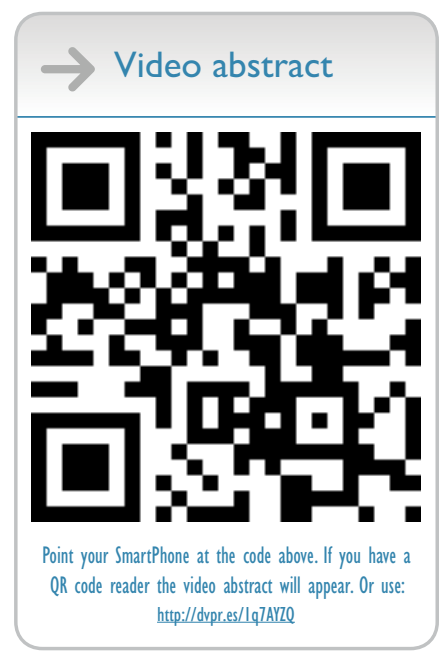

Correspondence: Monica Miozzo Division of Pathology, Fondazione Ca' Granda Ospedale Maggiore Policlinico, Via F Sforza 35, 20122 Milan, Italy

Tel +390250320250

Fax +390255032860

Email monica.miozzo@unimi.it

\begin{abstract}
Genomic imprinting is an epigenetically regulated mechanism leading to parental-origin allele-specific expression. Beckwith-Wiedemann syndrome (BWS) is an imprinting disease related to $11 \mathrm{p} 15.5$ genetic and epigenetic alterations, among them loss-of-function $C D K N 1 C$ mutations. Intriguing is that $C D K N 1 C$ gain-of-function variations were recently found in patients with IMAGe syndrome (intrauterine growth restriction, metaphyseal dysplasia, congenital adrenal hypoplasia, and genital anomalies). BWS and IMAGe share an imprinted mode of inheritance; familial analysis demonstrated the presence of the phenotype exclusively when the mutant $C D K N 1 C$ allele is inherited from the mother. Interestingly, both IMAGe and BWS are characterized by growth disturbances, although with opposite clinical phenotypes; IMAGe patients display growth restriction whereas BWS patients display overgrowth. CDKN1C codifies for CDKN1C/KIP2, a nuclear protein and potent tight-binding inhibitor of several cyclin/ Cdk complexes, playing a role in maintenance of the nonproliferative state of cells. The mirror phenotype of BWS and IMAGe can be, at least in part, explained by the effect of mutations on protein functions. All the IMAGe-associated mutations are clustered in the proliferating cell nuclear antigen-binding domain of CDKN1C and cause a dramatic increase in the stability of the protein, which probably results in a functional gain of growth inhibition properties. In contrast, BWS mutations are not clustered within a single domain, are loss-of-function, and promote cell proliferation. CDKN1C is an example of allelic heterogeneity associated with opposite syndromes.
\end{abstract}

Keywords: Beckwith-Wiedemann syndrome, IMAGe syndrome, CDKN1C, genomic imprinting, growth disturbances

\section{Introduction}

Genomic imprinting is an epigenetically regulated process determining parentalorigin allele-specific expression. Aberrant expression of imprinted genes characterizes imprinting diseases, including Beckwith-Wiedemann syndrome (BWS, OMIM 130650, chromosome 11p15.5). To date, eight imprinting diseases have been reported: Prader-Willi (OMIM 176270) and Angelman (OMIM 105830) syndromes (chromosome 15q11-q13), transient diabetes mellitus (OMIM 601410; chromosome 6q24), maternal/paternal uniparental disomy 14 syndromes (OMIM 608149; chromosome 14), Silver-Russell syndrome (SRS, OMIM 180860; chromosome 7 and 11p15), pseudohypoparathyroidism type IB syndrome (OMIM 603233; 20q13) and BWS. Generally, the chromosomal regions subjected to imprinting contain genes that are involved in growth and development (eg, IGF2 and H19). ${ }^{1,2}$ This statement is in accordance with the model of the "struggle of the sexes", based on the observation 
that paternally expressed genes are often growth promoting, while maternally expressed ones are growth inhibiting. ${ }^{3}$

Genetic and epigenetic alterations in BWS involve the imprinted chromosomal region 11 p15.5 containing genes with expression controlled by two neighboring imprinted domains, ie, ICR1 (imprinting control region 1, regulating IGF2/H19 genes) and ICR2 (regulating KCNQ1/CDKN1C genes). ICR 1 is imprinted in the male germline and operates as an insulator; ICR2 is imprinted in the female germline and acts as a promoter for the regulatory noncoding RNA KCNQ1OT1. ${ }^{4}$ The pathogenetic alterations recognized in BWS (Table 1) comprise CDKN1C loss-of-function mutations present in the maternally derived allele.

The $11 \mathrm{p} 15.5$ region is also involved in another two syndromes with imprinting defects: SRS and the IMAGe (intrauterine growth retardation, metaphyseal dysplasia, adrenal hypoplasia congenita, and genital anomalies syndrome, OMIM 614732). IMAGe syndrome is not due to primary imprinting defects such as BWS and SRS, and is exclusively related to mutations of $C D K N 1 C$. $^{5}$ This gene contains three exons and encodes p57(KIP2), a potent tight-binding inhibitor of several G1 cyclin/Cdk complexes (cyclin E-CDK2, cyclin D2-CDK4, and cyclin A-CDK2). ${ }^{6}$ It is a negative regulator of cell proliferation, playing a role in the maintenance of the nonproliferative state throughout life, probably acting as a tumor suppressor gene. $C D K N 1 C$ is expressed in the placenta, heart, brain, lung, skeletal muscle, kidney, pancreas, and testis, in the eye, and in the subcapsular or developing definitive zone of the adrenal gland. It is paternally imprinted, with a preferential expression of the maternal allele; ${ }^{7}$ however, the imprint is not absolute, as the paternal allele is also expressed at levels comparable with the maternal one in the fetal brain. ${ }^{8}$
The codified protein consists of three distinct domains, ie, a cyclin-dependent kinase inhibitory domain, a proline and alanine repeat domain, and a QT domain (Figure 1). The cyclin-dependent kinase inhibitory domain contains a cyclinbinding region; the proline and alanine repeats interact with the LIM domain kinase 1 and regulate actin dynamics; the proliferating cell nuclear antigen (PCNA) binding domain, able to prevent DNA replication in vitro and S-phase entry in vivo. ${ }^{6}$ As in the $R E T$ gene, ${ }^{9}$ different mutations in $C D K N 1 C$ can give rise to different phenotypes.

\section{Beckwith-Wiedemann syndrome}

The Beckwith-Wiedemann syndrome, described for the first time in 1963 by Beckwith, and again in 1964 by Wiedemann, is the most common overgrowth syndrome, with an incidence of about one in 13,700 live births. ${ }^{10,11}$ This occurrence is probably underestimated as milder phenotypes may not be ascertained. ${ }^{12}$ Males and females are affected equally, with the exception of monozygotic twins who show a female predominance. ${ }^{13}$ BWS occurs sporadically in most cases (85\%), with the remaining cases having autosomal dominant inheritance. $^{14}$

\section{Clinical diagnosis}

Clinical findings of BWS include macrosomia, macroglossia, abdominal wall defects (diastasis recti, omphalocele, or umbilical hernia), visceromegaly, hemihyperplasia, anterior ear creases and posterior helical pits, kidney abnormalities (medullary dysplasia, later development of medullary sponge kidney), cytomegaly of the adrenal fetal cortex, a positive family history of BWS, and, rarely, cleft palate. Height and weight are typically around the 97 th percentile in children,

Table I Molecular heterogeneity of BWS

\begin{tabular}{|c|c|c|c|}
\hline Genetic mechanisms & Occurrence (\%) & Methods of detection & Genotype/phenotype correlations \\
\hline Paternal UPD & $10-20$ & $\begin{array}{l}\text { Microsatellite/SNP analysis, } \\
\text { Southern blot, MS-MLPA, } \\
\text { pyrosequencing, mass } \\
\text { spectrometry }\end{array}$ & $\begin{array}{l}\text { Hemihyperplasia, high risk of Wilms' } \\
\text { tumor and hepatoblastoma, severe } \\
\text { phenotype (high level of somatic } \\
\text { mosaicism UPD) }\end{array}$ \\
\hline ID at ICRI (gain of methylation) & $2-8$ & $\begin{array}{l}\text { Southern blot, MS-MLPA, } \\
\text { pyrosequencing, mass spectrometry }\end{array}$ & $\begin{array}{l}\text { Macrosomia, macroglossia, } \\
\text { hemihyperplasia, high risk of Wilms' } \\
\text { tumor and hepatoblastoma }\end{array}$ \\
\hline ID at ICR2 (loss of methylation) & $50-60$ & $\begin{array}{l}\text { Southern blot, MS-MLPA, } \\
\text { pyrosequencing, mass spectrometry }\end{array}$ & Hemihyperplasia, omphalocele \\
\hline Paternal I Ip structural rearrangements & $\mathrm{I}-2$ & $\mathrm{FISH}, \mathrm{aCGH}$ & Developmental delay \\
\hline $\begin{array}{l}\text { Mutations of the maternal } \\
C D K N / C \text { allele }\end{array}$ & $\begin{array}{l}\text { 5-10 (sporadic cases) } \\
40 \text { (AD trait) }\end{array}$ & Sequencing & $\begin{array}{l}\text { Cleft palate, omphalocele, genital } \\
\text { anomalies, neuroblastoma }\end{array}$ \\
\hline
\end{tabular}

Notes: In column 4, the clinical features associated with the different genetic mechanisms are reported. The description is not exhaustive of the whole clinical presentation of BWS. Abbreviations: BWS, Beckwith-Wiedemann syndrome; UPD, uniparental disomy; ICR, imprinting control region; ID, imprinting defects; AD, autosomal dominant; FISH, fluorescent in situ hybridization; aCGH, array comparative genomic hybridization; MS-MLPA, methylation specific-multiplex ligation-dependent probe amplification; SNP, single nucleotide polymorphism. 


\section{CDKN1C mutations in}

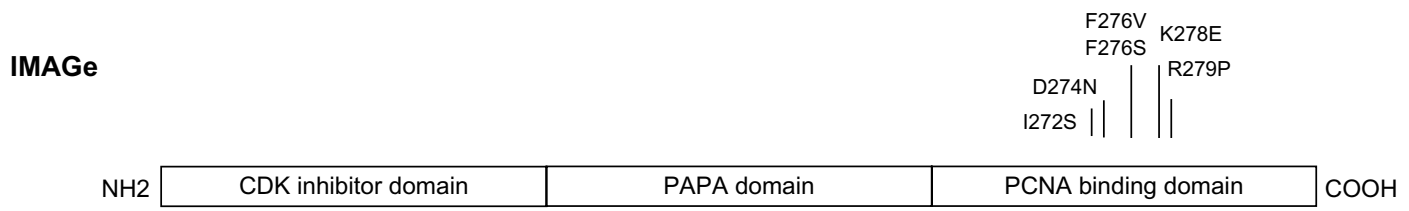

BWS
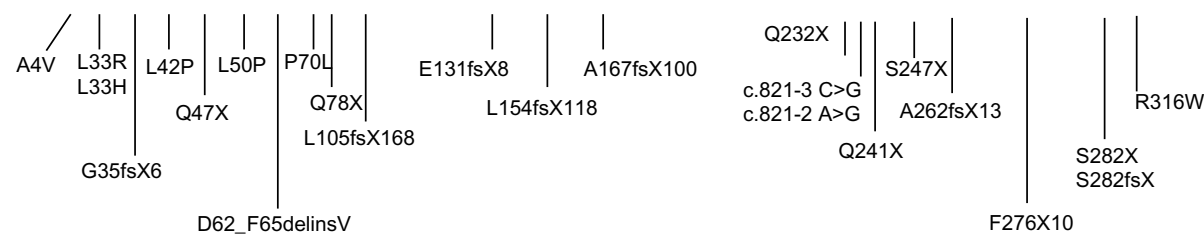

Figure I Mutations of CDKNIC in IMAGe syndrome (upper part) and BWS (lower part). The mutations in IMAGe syndrome are clustered within the PCNA-binding domain and are considered gain-of-function. The pathogenetic variations in BWS are spread throughout the gene and considered loss-of-function. The mutations reported here were previously described by Romanelli et a ${ }^{29}$ and by Hamajima et al..$^{48}$

Abbreviations: BWS, Beckwith-Wiedemann syndrome; IMAGe, intrauterine growth restriction, metaphyseal dysplasia, congenital adrenal hypoplasia, and genital anomalies; PCNA, proliferating cell nuclear antigen.

with head size closer to the 50th percentile, while adult height generally settles in the normal range. ${ }^{11,15,16}$ Additional findings may include neonatal hypoglycemia, nevus flammeus, cardiomegaly, structural cardiac defects, cardiomyopathy, advanced bone age, and a characteristic facial appearance. Most BWS patients have normal psychomotor development, but mental retardation has been noted in cases with chromosomal abnormalities and/or perinatal complications. ${ }^{17}$

Pregnancies with fetuses affected with BWS may be complicated by polyhydramnios, large/dysplastic placenta, ${ }^{16,18}$ a long and thickened umbilical cord, and an increased risk for premature delivery. ${ }^{16}$ Children conceived by in vitro fertilization are at increased risk of developing BWS, and the overall risk of BWS with in vitro fertilization is about one in 4,000. ${ }^{19-21}$

Although consensus diagnostic criteria for BWS have not been defined, the presence of three major features (eg, prenatal and postnatal overgrowth, macroglossia, and abdominal wall defects) or two major features and one minor feature (eg, ear anomalies, neonatal hypoglycemia, nephromegaly, and hemihyperplasia) is required for the postnatal clinical diagnosis of BWS. 4,22

Early diagnosis of BWS is crucial because of the well documented increased risk of cancer, most commonly Wilms' tumor and hepatoblastoma, but also adrenocortical carcinoma, rhabdomyosarcoma, and neuroblastoma. ${ }^{11,14,15,23-25}$ Isolated hemihyperplasia (OMIM 235000) is a congenital overgrowth disorder related to BWS that displays asymmetric involvement of the body. It may manifest few of the abnormal features associated with BWS; however, patients with isolated hemihyperplasia have an increased risk for embryonal tumors, primarily Wilms' tumor and hepatoblastoma, which are usually diagnosed before 10 years of age. ${ }^{26}$ Furthermore, BWS patients with hemihyperplasia have a four-fold increased tumor risk compared with BWS patients without hemihyperplasia, emphasizing the increased risk of tumors in isolated hemihyperplasia. ${ }^{25}$ Isolated hemihyperplasia cases should also be included in the specific follow-up created for BWS patients (Figure 2) ${ }^{27}$

\section{Molecular genetic testing}

Molecular diagnosis is important to confirm the provisional BWS clinical diagnosis and to identify BWS patients with cancer susceptibility. An etiologic molecular heterogeneity is clearly evident in BWS, due to various genetic and/or epigenetic alterations in growth regulatory genes located on the chromosome $11 \mathrm{p} 15$ region.

The genetic and epigenetic abnormalities associated with BWS are listed in Table 1 and include loss of methylation on the maternal chromosome at IC2, gain of methylation on the maternal chromosome at IC1, paternal uniparental disomy for chromosome $11 \mathrm{p} 15$ (usually as mosaicism), mutations in the CDKNIC gene, and cytogenetically detectable or submicroscopic genomic alteration within $11 \mathrm{p} 15.5 .{ }^{22,28} \mathrm{CDKN} 1 \mathrm{C}$ mutations are found in about $5 \%-10 \%$ of sporadic cases, whereas dominant maternal transmission of germline mutations are found in $40 \%$ of familial BWS cases. ${ }^{4,11}$

It is largely accepted that the variability of oncologic risk in BWS mostly depends on genetic heterogeneity (Figure 2) and duration of the observation. It is now well established that patients with a molecular abnormality 


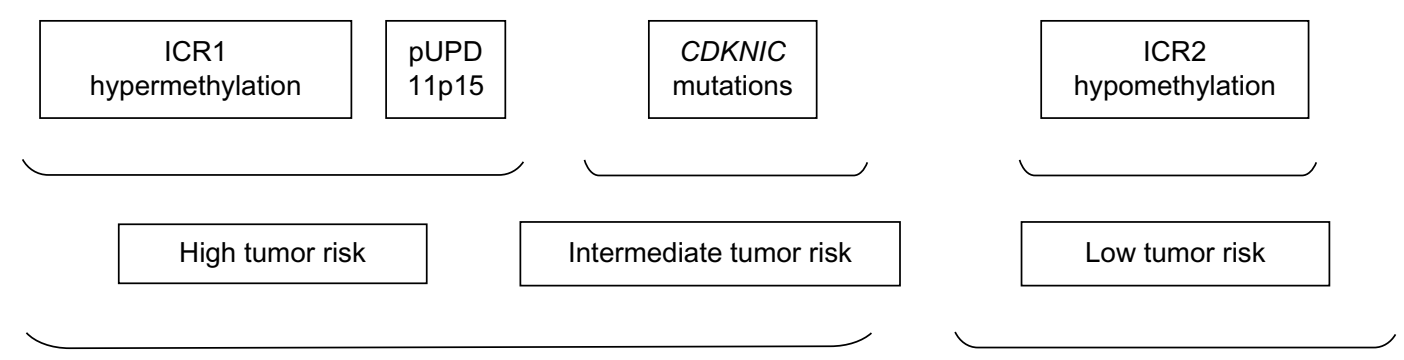

0-12 months: monthly clinical

examination + abdominal US every 3 months

1-6 years: abdominal US every 3 months and clinical examination between US scans

$>6$ years: yearly clinical examinations

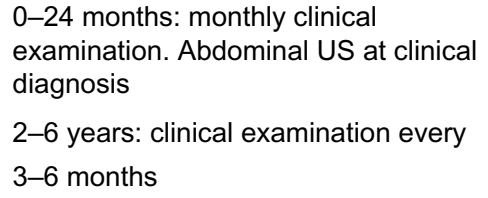

2-6 years: clinical examination every

3-6 months

Figure 2 Suggested follow-up for BWS according to risk classes.

Abbreviations: BWS, Beckwith-Wiedemann syndrome; PUPD, paternal uniparental disomy; ICR, imprinting control region; US, ultrasound.

of the telomeric domain (ICR1 hypermethylation) and 11 p15 paternal uniparental disomy have an increased risk of embryonal tumors (especially Wilms' tumor), whereas patients with defects of the centromeric domain only (ICR2 hypomethylation and CDKN1C mutations) are at lower risk of such tumors. ${ }^{22}$

\section{CDKN IC mutations in BWS: genotype-phenotype correlations}

Focusing on $C D K N 1 C$ mutations, subfertility in males, predisposition to aneurysmal arterial dilation, renal abnormalities, hearing loss, and, perhaps, increased risk for adultonset malignancy are known. ${ }^{12}$ Romanelli et al ${ }^{29}$ reviewed the CDKN1C-related phenotypic features in BWS patients, and suggested that these patients show a peculiar pattern of clinical malformations in comparison with those with other molecular defects, and therefore the peculiar clinical presentation of the patients can be useful to address the molecular analysis. Genotype-phenotype studies indicate that mutations in $C D K N 1 C$ are more frequently associated with omphalocele, ${ }^{30}$ clefting, ${ }^{31}$ and genital anomalies ${ }^{29,32}$ and less frequently with development of tumors, ${ }^{30}$ with the exception of rare cases with neuroblastoma. ${ }^{33-35}$ Focusing on cleft palate, although this finding has been rarely reported in patients affected by BWS $(2.5 \%),{ }^{15,29,36-39}$ it has usually been associated with $C D K N 1 C$ alterations; instead, cleft lip has never been documented in these patients.

In addition, CDKN1C seems to be highly expressed in the placenta, and therefore may have importance in the pathophysiology of pre-eclampsia/HELLP syndrome during pregnancy. ${ }^{40}$ Furthermore, a few patients with other rare malformations such as polydactyly and supernumerary nipples have been reported. ${ }^{29}$

\section{IMAGe syndrome}

IMAGe syndrome is a rare developmental disorder, mainly characterized by growth restriction and described for the first time in 1999 by Vilain et al. ${ }^{41}$ To date, there are only 12 familial or isolated cases reported in the literature, but this condition could be underestimated as the causative gene and the mode of inheritance have only recently been identified by Arboleda et al. ${ }^{5}$

\section{Clinical features}

The acronym IMAGe indicates the presence of Intrauterine growth restriction, Metaphyseal dysplasia, congenital Adrenal hypoplasia, and Genital anomalies. The first sign that becomes evident after birth is adrenal insufficiency, which can be severe and life-threatening if not recognized and treated early; it usually manifests in the first days of life with adrenal crises, but a case of late onset has been reported. ${ }^{42}$ Radiologic identification of metaphyseal dysplasia is often crucial for the diagnosis, but this could be very mild and identifiable only in late infancy or in childhood and then progress with age. A more precocious sign, ie, delayed endochondral ossification associated with osteopenia, hypercalcemia, and/ or hypercalciuria, can be present at birth and normalizes later in infancy. ${ }^{43,44}$ Growth hormone deficiency has also been described in some patients, ${ }^{40}$ and it has been shown that an early substitutive therapy assessment could help to improve the linear growth.

Dysmorphic craniofacial features in IMAGe syndrome include nonspecific signs, such as prominent forehead, 
low-set ears, flat nasal bridge, and short nose, while genital abnormalities seem to be confined to males and include micropenis, undescended testes, and varying severity of hypospadias. ${ }^{42}$

\section{Molecular genetic testing}

The IMAGe causative gene and inheritance model have been recently identified. ${ }^{5,45-47}$ To date, six missense mutations, all of them occurring in the PCNA-binding domain in the carboxy-terminal region of CDKN1C, were reported (Figure 1). ${ }^{5,45}$ Recently, Hamajima et $\mathrm{al}^{48}$ demonstrated that the IMAGe-associated mutations cause a dramatically increased instability of the CDKN1C proteins that probably results in a functional gain. This hypothesis is also supported by evidence of $C D K N 1 C$ truncation mutants lacking PCNA binding (ie, F276X10; Figure 1) identified in BWS patients showing the loss-of-function phenotype of $C D K N 1 C{ }^{49}$

For molecular diagnosis of IMAGe syndrome, $C D K N 1 C$ sequencing is recommended. Notably, familial analysis demonstrated de novo mutations or an imprinted mode of inheritance, exclusively with maternal transmission of the mutation. This means that each child of a woman heterozygous for the CDKN1C mutation has a $50 \%$ chance of inheriting the pathogenic variant and being affected, whereas each child of a man with the mutation has a $50 \%$ chance of inheriting the $C D K N 1 C$ pathogenic variant but is expected to be unaffected. ${ }^{50}$ This pattern of transmission suggests that IMAGe can be considered as an imprinting disease, albeit characterized by point gene mutations.

\section{Same gene, mirror phenotypes}

The mechanisms underlying genomic imprinting are very complex, in particular regarding the 11 p15.5 imprinted region. Indeed, different mutations (or epimutations) in the same gene (CDKN1C) or imprinted region can result in opposite phenotypes. $C D K N 1 C$ can be associated with BWS, SRS, and IMAGe syndrome, and IC1 opposite imprinting defects with BWS (IC1 hypermethylation) and SRS (IC1 hypomethylation). Among these syndromes, BWS is mainly characterized by overgrowth, and IMAGe and SRS by growth restriction. ${ }^{46} \mathrm{~A}$ detailed description of the mirror phenotype in BWS and IMAGe is reported in Table 2.

BWS-associated $C D K N 1 C$ mutations are most often truncating mutations distributed throughout the gene, or missense mutations in the aminoterminal CDK inhibitor domain, and those associated with IMAGe are missense variants in
Table 2 Mirror phenotypes in BWS and IMAGe syndrome

\begin{tabular}{|c|c|}
\hline BWS & IMAGe syndrome \\
\hline Macrosomia/hemihyperplasia & Short stature \\
\hline Abdominal wall defects & - \\
\hline $\begin{array}{l}\text { Visceromegaly, macroglossia, increased } \\
\text { risk of cancer }\end{array}$ & - \\
\hline Adrenal hyperplasia & Adrenal hypoplasia \\
\hline $\begin{array}{l}\text { Anterior ear creases, posterior helical pits, } \\
\text { cleft palate, nevus flammeus }\end{array}$ & - \\
\hline $\begin{array}{l}\text { Kidney abnormalities (cytomegaly } \\
\text { of the adrenal fetal cortex, medullary } \\
\text { dysplasia, delayed development of medullary } \\
\text { sponge kidney), increased risk of cancer }\end{array}$ & Adrenal insufficiency \\
\hline Neonatal hypoglycemia & - \\
\hline Structural cardiac defects & - \\
\hline Advanced bone age & $\begin{array}{l}\text { Delayed endochondral } \\
\text { ossification associated } \\
\text { with osteopenia, } \\
\text { hypercalcemia, and/or } \\
\text { hypercalciuria }\end{array}$ \\
\hline $\begin{array}{l}\text { Fetal macrosomia (LGA), polyhydramnios, } \\
\text { large/dysplastic placenta, long and } \\
\text { thickened umbilical cord, increased } \\
\text { risk for premature delivery }\end{array}$ & $\begin{array}{l}\text { Intrauterine growth } \\
\text { restriction }\end{array}$ \\
\hline- & Metaphyseal dysplasia \\
\hline- & $\begin{array}{l}\text { Micropenis, undescendec } \\
\text { testes, and varying } \\
\text { severity of hypospadias }\end{array}$ \\
\hline
\end{tabular}

Abbreviations: BWS, Beckwith-Wiedemann syndrome; IMAGe, intrauterine growth restriction, metaphyseal dysplasia, congenital adrenal hypoplasia, and genital anomalies; LGA, large for gestational age; SGA, small for gestational age.

the PCNA-binding domain (Figure 1), suggesting that the mutations causing these two imprinting disorders have different biologic consequences.

CDKN1C mutations in BWS act as a "double-negative", promoting proliferation due to loss of cell cycle inhibition, and then predisposition to cancer. In contrast, IMAGe syndrome is caused by mutations leading to a gain-of-function of CDKN1C protein, most probably related to increased stability of the protein. ${ }^{5}$ IMAGe-associated mutations inhibit binding to PCNA and ubiquitination of CDKN1C. Evidence for a gain-of-function effect was detected in Drosophila melanogaster, in which expression of the mutant but not the wild-type human protein reduced eye and wing size. ${ }^{5}$ It is conceivable that $C D K N 1 C$ mutations in IMAGe patients can trigger an excess of inhibition of growth and differentiation.

A good example of the effects of these mutations on the single organ has been provided by Arboleda et al, ${ }^{5}$ who showed how CDKN1C was strongly expressed during the embryonic development of the adrenal glands in mice. In BWS, the decreased inhibition of G1 CDKs due to loss-offunction mutations causes adrenal cytomegaly (one of the 
most common signs in BWS fetuses) and adrenocortical tumors (also sporadic adrenocortical tumors can display CDKN1C inactivation), while in IMAGe syndrome the increased inhibition of the cell cycle due to augmented stability of CDKN1C results in congenital adrenal hypoplasia (Table 2).

Finally, in the fetal brain, as mentioned before, $C D K N 1 C$ is biparentally expressed. This observation could explain why the occipitofrontal circumference in IMAGe syndrome is relatively well preserved in comparison with length/height and weight that are severely compromised. ${ }^{45}$

The link between the nature of CDKN1C mutation and the mirror phenotype of BWS and IMAGe can be explained by the importance of p57Kip2 in embryogenesis, which is also highlighted by the finding that knockout mice exhibit gastrointestinal tract defects, omphalocele, abnormal endochondral ossification, cleft palate, adrenal cortex enlargement, renal medullary dysplasia, increased body weight, and placental abnormalities. p57Kip2 excess in mice increases embryonic lethality and decreases body size, suggesting that embryonic growth requires accurate control of p57Kip2 dosage. ${ }^{51}$

In conclusion, after the discovery that SRS is characterized by the opposite growth defect compared with BWS, IMAGe syndrome represents an additional imprinting disorder with a mirror phenotype of BWS, strengthening the primary role of the $11 \mathrm{p} 15.5$ imprinted region in prenatal and postnatal growth regulation.

\section{Disclosure}

The authors report no conflicts of interest in this work.

\section{References}

1. Miozzo M, Simoni G. The role of imprinted genes in fetal growth. Biol Neonate. 2002;81:217-228.

2. Tabano S, Colapietro P, Cetin I, et al. Epigenetic modulation of the IGF2/H19 imprinted domain in human embryonic and extra-embryonic compartments and its possible role in fetal growth restriction. Epigenetics. 2010;16;5:313-324.

3. Jurkowska RZ, Jeltsch A. Genomic imprinting - the struggle of the genders at the molecular level. Angew Chem Int Ed Engl. 2013;52: 13524-13536.

4. Choufani S, Shuman C, Weksberg R. Beckwith-Wiedemann syndrome. Am J Med Genet C Semin Med Genet. 2010;154C:343-354.

5. Arboleda VA, Lee H, Parnaik R, et al. Mutations in the PCNAbinding domain of CDKN1C cause IMAGe syndrome. Nat Genet. 2012;44:788-789.

6. Lee MH, Reynisdottir I, Massague J. Cloning of p57(KIP2), a cyclindependent kinase inhibitor with unique domain structure and tissue distribution. Genes Dev. 1995;9:639-649.

7. Hatada I, Mukai T. Genomic imprinting of p57KIP2, a cyclin-dependent kinase inhibitor, in mouse. Nat Genet. 1995;11:204-206.

8. Matsuoka S, Thompson JS, Edwards MC, et al. Imprinting of the gene encoding a human cyclin-dependent kinase inhibitor, p57KIP2, on chromosome 11p15. Proc Natl Acad Sci U S A. 1996;93:3026-3030.
9. Marx SJ. Molecular genetics of multiple endocrine neoplasia types 1 and 2. Nat Rev Cancer. 2005;5:367-375.

10. Engström W, Lindham S, Schofield P. Wiedemann-Beckwith syndrome. Eur J Pediatr. 1988;147:450-457.

11. Weksberg R, Shuman C, Beckwith JB. Beckwith-Wiedemann syndrome. Eur J Hum Genet. 2010;18:8-14.

12. Greer KJ, Kirkpatrick SJ,Weksberg R, Pauli RM. Beckwith-Wiedemann syndrome in adults: observations from one family and recommendations for care. Am J Med Genet Part A. 2008;146A:1707-1712.

13. Bliek J, Alders M, Maas SM, et al. Lessons from BWS twins: complex maternal and paternal hypomethylation and a common source of haematopoietic stem cells. Eur J Hum Genet. 2009;17:1625-1634.

14. Cohen MM Jr. Beckwith-Wiedemann syndrome: historical, clinicopathological, and etiopathogenetic perspectives. Pediatr Dev Pathol. 2005;8:287-304.

15. Pettenati MJ, Haines JL, Higgins RR, Wappner RS, Palmer CG, Weaver DD. Wiedemann-Beckwith syndrome: presentation of clinical and cytogenetic data on 22 new cases and review of the literature. Hum Genet. 1986;74:143-154.

16. Weng EY, Moeschler JB Jr, Graham JM. Longitudinal observations on 15 children with Wiedemann-Beckwith syndrome. Am J Med Genet. 1995;56:366-373.

17. Munns C, Batch J. Hyperinsulinism and Beckwith-Wiedemann syndrome. Arch Dis Child Fetal Neonatal Ed. 2001;84:F67-F69.

18. Wilson M, Peters G, Bennetts B, et al. The clinical phenotype of mosaicism for genome-wide paternal uniparental disomy: two new reports. Am J Med Genet. 2008;146A:137-148.

19. Gosden R, Trasler J, Lucifero D, Faddy M. Rare congenital disorders, imprinted genes, and assisted reproductive technology. Lancet. 2003;361:1975-1977.

20. Halliday J, Oke K, Breheny S, Algar E. Beckwith-Wiedemann syndrome and IVF: a case control study. Am J Hum Genet. 2004;75:526e8.

21. Strawn EY Jr, Bick D, Swanson A. Is it the patient or the IVF? BeckwithWiedemann syndrome in both spontaneous and assisted reproductive conceptions. Fertil Steril. 2010;94:754. e1-754. e2.

22. Calvello M, Tabano S, Colapietro P, et al. Quantitative DNA methylation analysis improves epigenotype-phenotype correlations in BeckwithWiedemann syndrome. Epigenetics. 2013;8:1053-1060.

23. Wiedemann HR. Tumors: an hemihypertrophy associated with Wiedemann-Beckwith syndrome. Eur J Pediatr. 1983;141:129.

24. Tan TY, Amor DJ. Tumour surveillance in Beckwith-Wiedemann syndrome and hemihyperplasia: a critical review of the evidence and suggested guidelines for local practice. J Paediatr Child Health. 2006;42:486-490.

25. DeBaun MR, Tucker MA. Risk of cancer during the first four years of life in children from the Beckwith-Wiedemann Syndrome Registry. J Pediatr. 1998;132:398-400.

26. Clericuzio CL, Martin RA. Diagnostic criteria and tumor screening for individuals with isolated hemiphyperplasia. Genet Med. 2009;11: 220-222.

27. Brioude F, Lacoste A, Netchine I, et al. Beckwith-Wiedemann syndrome: growth pattern and tumor risk according to molecular mechanism, and guidelines for tumor surveillance. Horm Res Paediatr. 2013;80:457-465.

28. Shuman C, Beckwith JB, Smith AC, Weksberg R. Beckwith-Wiedemann syndrome. December 14, 2010. In: Pagon RA, Adam MP, Bird TD, et al, editors. GeneReviews ${ }^{\circledR}$. Seattle, WA, USA: University of Washington, Seattle; 1993-2014. Available from: http://www.ncbi.nlm.nih.gov/ books/NBK1394/. Accessed July 30, 2014.

29. Romanelli V, Belinchón A, Benito-Sanz S, et al. CDKN1C (p57(Kip2)) analysis in Beckwith-Wiedemann syndrome (BWS) patients: genotypephenotype correlations, novel mutations, and polymorphisms. Am JMed Genet A. 2010;152A:1390-1397.

30. Lam WW, Hatada I, Ohishi S, et al. Analysis of germline CDKN1C (p57KIP2) mutations in familial and sporadic Beckwith-Wiedemann syndrome (BWS) provides a novel genotype-phenotype correlation. J Med Genet. 1999;36:518-523. 
31. Weksberg R, Shuman C, Smith AC. Beckwith-Wiedemann syndrome. Am J Med Genet Part C. 2005;137C:12-23.

32. Welsh HI, Stockley TL, Parkinson N, Ardinger HH. CDKN1C mutations and genital anomalies. Am J Med Genet A. 2012;158A:265.

33. Bliek J, Maas SM, Ruijter JM, et al. Increased tumour risk for BWS patients correlates with aberrant $\mathrm{H} 19$ and not KCNQ1OT1 methylation: occurrence of KCNQ1OT1 hypomethylation in familial cases of BWS. Hum Mol Genet. 2001;10:467-476.

34. Weksberg R, Nishikawa J, Caluseriu O, et al. Tumor development in the Beckwith Wiedemann syndrome is associated with a variety of constitutional molecular $11 \mathrm{p} 15$ alterations including imprinting defects of KCNQ1OT1. Hum Mol Genet. 2001;10:2989-3000.

35. Chitayat D, Friedman JM, Dimmick JE. Neuroblastoma in a child with Wiedemann Beckwith syndrome. Am J Med Genet Part C. 2010;35: 433-436.

36. Delgado A, Lozano MJ, Ruffa G, et al. Beckwith-Wiedemann syndrome. Presentation of 5 cases. Minerva Pediatr. 1975;27:245-261.

37. Elliott M, Bayly R, Cole T, Temple IK, Maher ER. Clinical features and natural history of Beckwith-Wiedemann syndrome: Presentation of 74 new cases. Clin Genet. 1994;46:168-174.

38. Kim Y, Shibutani T, Hirota Y, Mahbub SF, Matsuura H. Anesthetic considerations of two sisters with Beckwith-Wiedemann syndrome. Anesth Prog. 1996;43:24-28.

39. Laroche C, Testelin S, Devauchelle B. Cleft palate and Beckwith-Wiedemann syndrome. Cleft Palate Craniofac J. 2005;42: 212-217.

40. Romanelli V, Belinchon A, Campos-Barros A, et al. CDKN1C mutations in HELLP/preeclamptic mothers of Beckwith-Wiedemann syndrome (BWS) patients. Placenta. 2009;30:551-554.

41. Vilain E, Le Merrer M, Lecointre C, et al. IMAGe, a new clinical association of intrauterine growth retardation, metaphyseal dysplasia, adrenal hypoplasia congenita, and genital anomalies. J Clin Endocrinol Metab. 1999;84:4335-4340.
42. Pedreira CC, Savarirayan R, Zacharin MR. IMAGe syndrome: a complex disorder affecting growth, adrenal and gonadal function, and skeletal development. J Pediatr. 2004;144:274-277.

43. Amano N, Naoaki H, Ishii $\mathrm{T}$, et al. Radiological evolution in IMAGe association: a case report. Am J Med Genet A. 2008;146A: 2130-2133.

44. Balasubramanian M, Sprigg A, Johnson DS. IMAGe syndrome: case report with a previously unreported feature and review of published literature. Am J Med Genet A. 2010;152A:3138-3142.

45. Kato F, Hamajima T, Hasegawa T, et al. IMAGe syndrome: clinical and genetic implications based on investigations in three Japanese patients. Clin Endocrinol (Oxf). 2014;80:706-713.

46. Soejima H, Higashimoto K. Epigenetic and genetic alterations of the imprinting disorder Beckwith-Wiedemann syndrome and related disorders. J Hum Genet. 2013;58:402-409.

47. Dias RP, Maher ER. An imprinted IMAGe: insights into growth regulation through genomic analysis of a rare disease. Genome Med. 2012;4:60.

48. Hamajima N, Johmura Y, Suzuki S, Nakanishi M, Saitoh S. Increased protein stability of CDKN1C causes a gain-of-function phenotype in patients with IMAGe syndrome. PLoS One. 2013;8:e75137.

49. Hatada I, Ohashi H, Fukushima Y, et al. An imprinted gene p57KIP2 is mutated in Beckwith-Wiedemann syndrome. Nat Genet. 1996;14:171-173.

50. Bennett J, Schrier Vergano S, Deardorff MA. IMAGe syndrome. In: Pagon RA, Adam MP, Bird TD, et al, editors. GeneReviews ${ }^{\circledR}$. Seattle, WA, USA: University of Washington, Seattle; 1993-2014. Available from: http://www.ncbi.nlm.nih.gov/books/NBK190103/. Accessed July 30, 2014.

51. Borriello A, Caldarelli I, Bencivenga D, et al. p57(Kip2) and cancer: time for a critical appraisal. Mol Cancer Res. 2011;9:1269-1284.
The Application of Clinical Genetics

\section{Publish your work in this journal}

The Application of Clinical Genetics is an international, peer-reviewed open access journal that welcomes laboratory and clinical findings in the field of human genetics. Specific topics include: Population genetics; Functional genetics; Natural history of genetic disease; Management of genetic disease; Mechanisms of genetic disease; Counseling and ethical

\section{Dovepress}

issues; Animal models; Pharmacogenetics; Prenatal diagnosis; Dysmorphology. The manuscript management system is completely online and includes a very quick and fair peer-review system, which is all easy to use. Visit http://www.dovepress.com/testimonials.php to read real quotes from published authors. 